\title{
Perinatal practice in extreme premature delivery: variation in Dutch physicians' preferences despite guideline
}

\author{
Rosa Geurtzen $^{1}$ - Jos Draaisma ${ }^{1} \cdot$ Rosella Hermens $^{2} \cdot$ Hubertina Scheepers $^{3}$. \\ Mallory Woiski ${ }^{4}$ - Arno van Heijst ${ }^{1} \cdot$ Marije Hogeveen ${ }^{1}$
}

Received: 29 February 2016 /Revised: 19 May 2016 / Accepted: 25 May 2016 /Published online: 1 June 2016

(C) The Author(s) 2016. This article is published with open access at Springerlink.com

\begin{abstract}
Decisions at the limits of viability about initiating care are challenging. We aimed to investigate physicians' preferences on treatment decisions, against the background of the 2010 Dutch guideline offering active care from $24^{+0 / 7}$ weeks of gestational age (GA). Obstetricians' and neonatologists' opinions were compared. An online survey was conducted amongst all perinatal professionals $(n=205)$ of the 10 Dutch level III perinatal care centers. Response rate was $60 \%(n=122)$. Comfort care was mostly recommended below $24^{+0 / 7}$ weeks and intensive care over $26^{+0 / 7}$ weeks. The professional views varied most at 24 and 25 weeks, with intensive care recommended but comfort care at parental request optional being the median. There was a wide range in perceived lowest limits of GA for interventions as a caesarian section and a neonatologist present at birth. Obstetricians and neonatologists disagreed on the lowest limit providing chest compressions and administering epinephrine for resuscitation. The main factors restricting active treatment were presence of congenital disorders, "small for gestational age" fetus, and incomplete course of corticosteroids.
\end{abstract}

Communicated by Patrick Van Reempts

Rosa Geurtzen

Rosa.Geurtzen@radboudumc.nl

1 Department of Pediatrics, Radboud university medical center Amalia Children's Hospital, Nijmegen, The Netherlands

2 Scientific Institute for Quality of Care, Radboud university medical center, Nijmegen, The Netherlands

3 Department of Gynecology, Maastricht UMC+, Maastricht, The Netherlands

4 Department of Gynecology, Radboud university medical center, Nijmegen, The Netherlands
Conclusion: There was a wide variety in individually preferred treatment decisions, especially when aspects were not covered in the Dutch guideline on perinatal practice in extreme prematurity. Furthermore, obstetricians and neonatologists did not always agree.

What is known:

- Cross-cultural differences exists in the preferred treatment at the limits of viability

- In the Netherlands since 2010, intensive care can be offered starting at $24^{+0 / 7}$ weeks gestation

What is new:

- There was a wide variety in preferred treatment decisions at the limits of viability especially when aspects were not covered in the Dutch national guideline on perinatal practice in extreme prematurity.

Keywords Limits of viability · Prenatal counseling $\cdot$ Extreme prematurity $\cdot$ Treatment decisions $\cdot$ Resuscitation

$\begin{array}{ll}\text { Abbreviations } \\ \text { CS } & \text { Caesarian section } \\ \text { GA } & \text { Gestational age(s) } \\ \text { IQR } & \text { Interquartile range } \\ \text { SGA } & \text { Small for gestational age }\end{array}$

\section{Introduction}

The advances in perinatal care have led to improved outcome in extreme prematurity. Gestational ages (GA) at which active treatment can be considered have decreased worldwide; however, a "gray zone" still remains $[2,6,31,35]$. Therefore, in daily practice, several decisions have to be made about the initiation of care at $23-25$ weeks GA. The key question is 
whether to initiate comfort care or active care. Factors that could be of influence are parental preferences and individual maternal or fetal characteristics. To support clinicians with decision-making in daily practice, several national guidelines on perinatal care are developed. Pignotti (2008), Gallagher (2014), and Guillen (2015) reviewed these guidelines and showed that 23 to 24 weeks of gestation are regarded as the gray zone of viability. In this gray zone, treatment decisions may be made using an individual approach and/or taking parental preferences into account. In some countries, this gray zone extends through to $25^{+67}$ weeks $[10,13,28]$. Not only guidelines differ, but also international, national, and local variations in actual practice do exist $[4,7,12,14,17,22,23,25$, 30]. Furthermore, surveys amongst perinatal professionals revealed variation in (preferred) treatment decisions at the lower limits of viability, for example, decisions on performing a caesarian section (CS) and resuscitation [5, 9, 20, 24, 26, 32, 33].

Accompanying the decision whether or not to initiate care, several other choices have to be made, such as transfer to a specialized hospital, antenatal administration of corticosteroids, monitoring of the fetus, delivery mode, presence of the neonatologist at birth, and the extent of potential resuscitation. Guidelines do not always cover all these aspects $[10,13,28]$. In 2010, the national Dutch guideline on perinatal practice in extremely premature delivery lowered the limit offering intensive care from $25^{+0 / 7}$ to $24^{+0 / 7}$ weeks GA [8]. Unlike in other countries, in the Netherlands, this lower limit is rather strict (in contrast to, i.e., the American AAP guideline advocating for an individualized approach) and, in general, intensive care will not be offered below 24 weeks GA [4, 8, 10, 13, 28]. The Dutch guideline states "informed consent of parents is prerequisite in the decision whether or not to initiate care at 24 weeks GA". It indicates that prognostic factors (such as weight, gender) can be taken into account in decision-making in individual cases. However, because the prognostic value of these factors is unknown for the Dutch population, no specific recommendations are given. Furthermore, the Dutch guideline recommends transfer to a tertiary center from $23^{+4 / 7}$ weeks GA for counseling, administration of corticosteroids from $23^{+5 / 7}$ weeks GA, and fetal monitoring with a CS can be considered in case of suspected fetal distress from $24^{+0 / 7} \mathrm{GA}$ in which the specific risks and benefits for current and future pregnancies and delivery need to be discussed.

Like in most guidelines, variable operationalization is imaginable. Disagreement between perinatal professional (individuals and/or groups) on treatment decisions in extremely preterm gestations could potentially lead to a conflict in perinatal care $[5,9,10,32]$. Therefore, our primary goal was to investigate Dutch physicians' preferences on decisions about treatment options for an extremely premature neonate against the background of this guideline. Our secondary goal was to study potential differences between neonatologists and obstetricians.

\section{Materials and methods}

\section{Study design}

Cross-sectional, multicenter study (PreCo survey) using an online survey.

\section{Setting and study population}

This study, the PreCo survey, is part of the larger PreCo study, which evaluates Dutch care on different levels in (imminent) extreme preterm birth, e.g., prenatal counseling and treatment decisions (clinicaltrials.gov, NCT02782650 \& NCT02782637). This PreCo study is supported and followed by both the national associations of neonatology and obstetrics as well as the patient association.

The Dutch care for extreme premature births is centralized in 10 level III centers for perinatal care which all gave informed consent to participate in the current study. Surveys were sent to all fellows and senior staff members in both obstetrics and neonatology. Data were collected from July 2012 through October 2013, approximately 2 to 3 years after the introduction of the new guideline on perinatal practice in extreme premature delivery in the Netherlands.

\section{Survey design and data collection}

The PreCo survey was developed in three stages. The first stage consisted of the development of a draft of the survey based on international literature about prenatal counseling; several prenatal counseling surveys that have kindly been shared with us $[1,3,5,18,19,27]$, observations from our previous study [11], and on public discussions generated by the Dutch guideline on perinatal practice in extreme premature delivery [8]. In the second stage, the survey was improved in two Delphi rounds; in the first round, the concept survey was extensively evaluated by four team members (two neonatologists, one obstetrician, and one pediatrician) and in the second round, independent perinatal experts (two neonatologists) pilot-tested the survey for clarity and content. In the third stage, the survey was adapted for both profession groups to exclude irrelevant questions and to optimize the participation rate. The PreCo survey required $\sim 20 \mathrm{~min}$ to complete.

We were particularly interested in physicians' preferences on treatment decisions. Therefore, we designed three questions: the first asking is for recommendations on whether or not to initiate intensive care at several extreme preterm GAs, the second asking is the personal lower limits in GA for various interventions potentially associated with extreme prematurity, and the third is on the importance of associated factors in recommending active treatment or not. We used a fictitious case of an "uncomplicated" extreme premature delivery to examine all these preferences. Finally, the last section of the 
entire survey contained demographical items such as age and years of experience.

An individual link to the online survey was sent to all participants. Three reminders were sent to non-responders. Survey results were anonymized before analysis. This study was waived by the local institutional review board.

Characteristics of the fictitious case

A consultation for prenatal counseling with an impending extreme premature delivery, singleton fetus, unremarkable history of pregnancy, average estimated fetal birth weight, unknown gender, no known congenital abnormalities, unremarkable social and medical history of parents, antenatal corticosteroids have been administered, and normal fetal heart rate registration.

\section{Data analysis}

Descriptive statistics were given as proportions of the respondents for that specific question. For comparison between obstetricians and neonatologists Chi-square $\left({ }^{2}\right)$, Fisher exact, or Mann-Whitney $\mathrm{U}$ tests were used when applicable. Exact $p$ values were provided, values $<0.05$ were considered significant. Statistical analyses were conducted using IBM SPSS Statistics (Version 20.0. Armonk, NY: IBM Corp).

\section{Results}

We received 122 surveys from 205 eligible professionals; a response rate of $60 \%$. Each perinatal center was represented. Of those, 45 were from obstetricians and 77 from neonatologists. Of all 122 returned surveys, eight were only partially completed. Obstetricians had fewer years of experience than the neonatologists (Table 1). There was no influence of age or years of experience on the results, but some differences based on the institute of the participant did exist.

Professionals gave their preferred recommendations about whether or not to initiate intensive care at each week of

Table 1 Characteristics of professionals

\begin{tabular}{|c|c|c|}
\hline & $\begin{array}{l}\text { Obstetricians } \\
(n=84 \text { sent })\end{array}$ & $\begin{array}{l}\text { Neonatologists } \\
(n=121 \text { sent })\end{array}$ \\
\hline Response rate & $54 \%$ & $64 \%$ \\
\hline Gender, $\%$ male & $32 \%$ & $69 \%$ \\
\hline \multirow{2}{*}{$\begin{array}{l}\text { Having children (parent) } \% \text { of } \\
\text { those: parent of premature } \\
\text { child ( }<27 \text { weeks) }\end{array}$} & $91 \%$ & $83 \%$ \\
\hline & $0 \%$ & $2 \%$ \\
\hline Median age in years (q25-75) & $40(38-47)$ & $45(37-50)$ \\
\hline $\begin{array}{l}\text { Years of experience, median } \\
\quad(\mathrm{q} 25-75)\end{array}$ & $5(1-10)^{*}$ & $9(4-17)$ \\
\hline
\end{tabular}

*p 0.02 (MWU) gestation, ranging from providing comfort care through providing intensive care (Fig. 1). At $22^{+0-6 / 7}$ weeks GA, recommending comfort care was the only option. For a birth at $23^{+0-6 / 7}$ weeks GA, $82 \%$ recommended comfort care only, but some professionals (16\%) also agreed with intensive care at parental request. At $24^{+0-6 / 7}$ and $25^{+0-6 / 7}$ weeks GA, the majority (54 and $64 \%$, respectively) recommended intensive care with the ability of comfort care at parental request; however, there was variation in the given preferences. At $26^{+0-6 / 7}$ and $27^{+0-6 / 7}$ weeks GA, the vast majority ( 89 and $96 \%$, respectively) recommended intensive care without the possibility of comfort care - however, a minority would agree with comfort care at parental request (11 and $4 \%$, respectively). No significant differences were found for any of the GAs between obstetricians and neonatologists.

Professionals were asked for their personal lower limits for certain interventions or decisions at extreme prematurity (Fig. 2). Answer options ranged from "starting at $22^{+0 / 7}$ weeks GA" through "starting at $26^{+0 / 7}$ weeks GA"; only at 23 weeks more detailed answer options were available $\left(23^{+0 / 7}, 23^{+4 / 7}\right.$, and $23^{+5 / 7}$ weeks GA). There was variation between individuals up to 4 weeks. Medians in weeks GA (for this lower limit) were as mentioned below and interquartile ranges (IQR) are provided (obstetricians and neonatologists had the same median except where otherwise stated):

Transfer pregnant woman with imminent premature delivery to tertiary hospital with NICU: $23^{+4 / 7}$ (IQRobstetricians $23^{+0 / 7}-23^{+5 / 7}$ neonatologists $23^{+4 / 7}-23^{+5 / 7}$ ).

Antenatal administration of corticosteroids: $23^{+.5 / 7}$ (IQRobstetricians $23^{+4 / 7}-23^{+5 / 7}$ neonatologists $23^{+5 / 7}-23^{+5 / 7}$ ).

Use of fetal monitor during delivery for monitoring of the fetal condition: $24^{+0 / 7} \quad$ (IQR both $24^{+0 / 7}-25^{+0 / 7}$ ).

Perform a CS on fetal indication: $25^{+0 / 7} \quad$ IQRobstetricians $24^{+0 / 7}-25^{+0 / 7}$ neonatologists $25^{+0 / 7}-26^{+0 / 7}$ ).

Neonatologists have to be present at the delivery: $24^{+0 / 7}$ (IQR both $\left.23^{+5 / 7}-24^{+0 / 7}\right)$.

Intubate after birth when necessary: $24^{+0 / 7} \quad$ (IQR both $\left.24^{+0 / 7}-24^{+0 / 7}\right)$.

Chest compressions after birth when necessary: obstetricians $25^{+0 / 7}$ and neonatologists $26^{+0 / 7}(p<0.01) \quad\left(\right.$ IQRobstetricians $24^{+0 / 7}-25^{+0 / 7}$ neonatologists $25^{+0 / 7}-26^{+0 / 7}$ ).

Administration of epinephrine after birth when necessary: obstetricians $25^{+0 / 7}$ and neonatologists $26^{+0 / 7}(p<0.01) \quad$ (IQRobstetricians $24^{+0 / 7}-25^{+0 / 7}$ neonatologists $\left.25^{+0 / 7}-26^{+0 / 7}\right)$.

There was a disagreement between both professional groups with obstetricians having a significant lower threshold on providing chest compressions and administering epinephrine than neonatologist. Furthermore, significant differences between institutes were found on fetal monitoring, CS, chest 


\begin{tabular}{|c|c|c|c|c|c|}
\hline & $\begin{array}{l}\text { Comfort care provided, } \\
\text { intensive care not offered }\end{array}$ & $\begin{array}{c}\text { Comfort care provided, } \\
\text { intensive care possible on } \\
\text { parental request }\end{array}$ & Neutral & $\begin{array}{c}\text { Intensive care provided, } \\
\text { comfort care possible on } \\
\text { parental request }\end{array}$ & $\begin{array}{l}\text { Intensive care provided, } \\
\text { comfort care not offered }\end{array}$ \\
\hline $27^{0 / 1}-27^{6 / \pi}$ & & & & ${ }^{*}$ oooo & 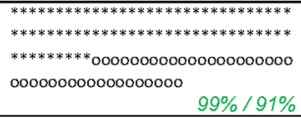 \\
\hline $\begin{array}{r}26^{0 / 7}-26^{6 / 7} \\
p 0,549 \\
\end{array}$ & & & & $* * * * * * * 000000$ & 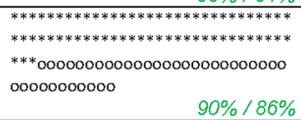 \\
\hline $\begin{array}{r}25^{0 / 1}-25^{6 / 1} \\
p 0,503 \\
\end{array}$ & & ${ }^{* *_{0}}$ & $* * * * * * * * 0000$ & $\begin{array}{l}\begin{array}{l}* * * * * * * * * * * * * * * * * * * * * * * * * * * * * * * * * * * \\
* * * * * * * * * * * * * * * * * \\
* 00000000000000\end{array} \\
\text { ocooooooooooocoo } 65 \% / 67 \%\end{array}$ & $\begin{array}{r}* * * * * * * * * * * * * * * 0000000 \\
21 \% / 16 \%\end{array}$ \\
\hline $\begin{array}{r}24^{0 / 1}-24^{6 / 1} \\
p 0,353\end{array}$ & & $* * * * * * * * 0000000000$ & 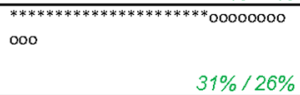 & 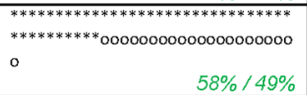 & $0 \% / 2 \%$ \\
\hline $23^{0 / 1}-23^{6 / 7}$ & 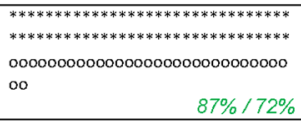 & *******\%o0000000000 & $3 \% / 2 \%$ & & \\
\hline $22^{0 / 1}-22^{6 / 1}$ & 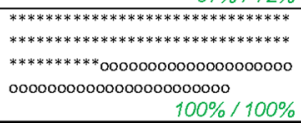 & & & & \\
\hline
\end{tabular}

Fig. 1 Recommendations for a pregnant woman who is about to deliver a fetus of the following gestational ages neonatologist $=*$ obstetrician $=o$ (individuals) $x x \% / x x \%=$ proportion of neonatologist/proportion of obstetricians

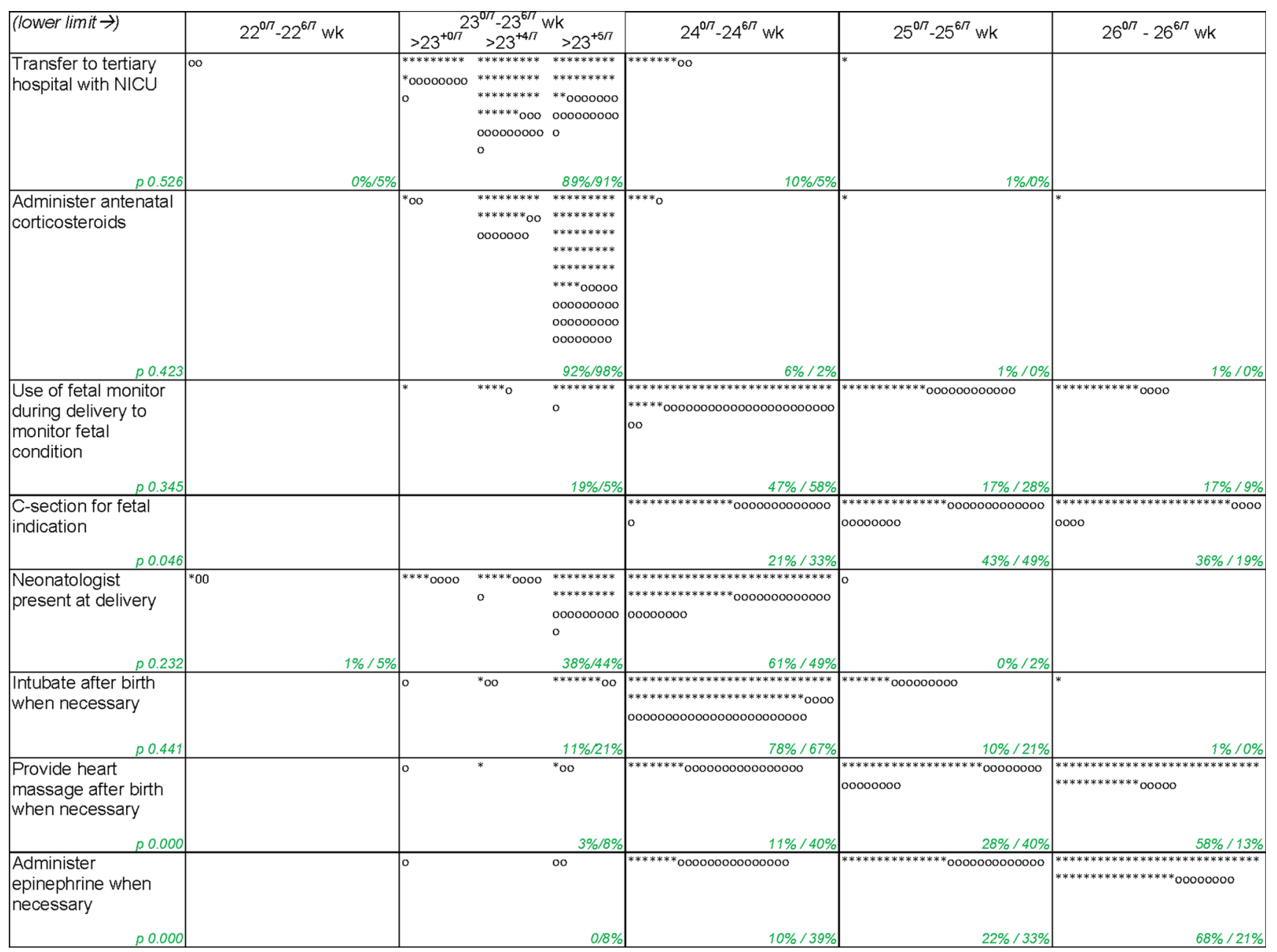

Fig. 2 Personal limits of various interventions that could be taken around a possible premature delivery neonatologist $=*$ obstetrician $=o$ $x x \% / x x \%=$ proportion of neonatologist/proportion of obstetricians 
compressions, and epinephrine, which may reflect local policies.

Figure 3 shows how certain factors could alter potential recommendations on initiating intensive care at $24^{+0 / 7}$ weeks GA. Ranked by the proportions of subjects being less likely to advise intensive treatment, congenital disorders was the strongest factor, followed by small for gestational age (SGA) infant, no antenatal administration of corticosteroids, and a disturbed fetal heart-rate. There were two items that differed between the two professional groups: first "no administration of corticosteroids"; this factor made $63 \%$ of obstetricians versus $40 \%$ of neonatologists less likely to advise intensive treatment ( $p=0.033$ ). Second for "SGA infant", $92 \%$ of neonatologists versus $76 \%$ of obstetricians were less likely to advise intensive treatment $(p=0.028)$. Significant differences between institutes were found on male gender, multiple pregnancy, and disturbed fetal monitor, so again, some local preferences seem to exist.

\section{Discussion}

This is the first study to assess professional preferences on treatment decisions in extreme prematurity in the Netherlands, particularly of neonatologists and obstetricians. There was a wide variation in preferred treatment decisions at the limits of viability, mostly when aspects were not covered in the Dutch national guideline on perinatal practice in extreme prematurity. This variation was shown between individual perinatal professionals on (a) the attitude towards the GA at which active treatment should be started, (b) the individual preferential lower limits of GA for certain interventions, and (c) the influence of additional patient characteristics on initiating care or not. Neonatologists' and obstetricians' opinions differed on the latter two.

\section{Recommendations on comfort versus intensive care}

Regarding the large variation between perinatal professionals, our findings are comparable to Kaempf (2006) and Tomlinson (2010) who also discovered variety at various GA [18,33]. At $<24^{+0 / 7}$ weeks, comfort care is preferred to be recommended, consistent with the Dutch guideline. However, for some physicians, intensive care is an option at 23 weeks of gestation at parental request and, although being internationally practiced, it is not supported in the Dutch national guideline [8, 10, 28]. At 24 weeks, the Dutch guideline requests agreement of parents when initiating intensive care, and only one participant preferred recommending intensive care treatment only without accepting a potential parental request for comfort care. However, the majority did give the recommendation to provide intensive care with comfort care only as an option at parental request. The Dutch guideline describes that "intensive care can be offered" at 24 weeks GA, without explicitly giving an advice on whether to present this as default or present as neutral option next to comfort care. Our results show that at 24 weeks, variety in preferences exists. It is known that presenting delivery room options for extremely premature infants as default exerts a significant effect on decision makers [16]. At 25 weeks gestation, there is similar variety.

Notable is that some physicians approve comfort care on parental request at 26 and 27 weeks. The Dutch guideline does not explicitly cover this GA [8]. Also, internationally, 26 and 27 weeks of gestation are in general not being seen as the gray zone of viability anymore and the initiation of intensive care at these GA is being seen as standard of care $[6,10,28,31]$. Kipnis argues that though treatment may offer a reasonable
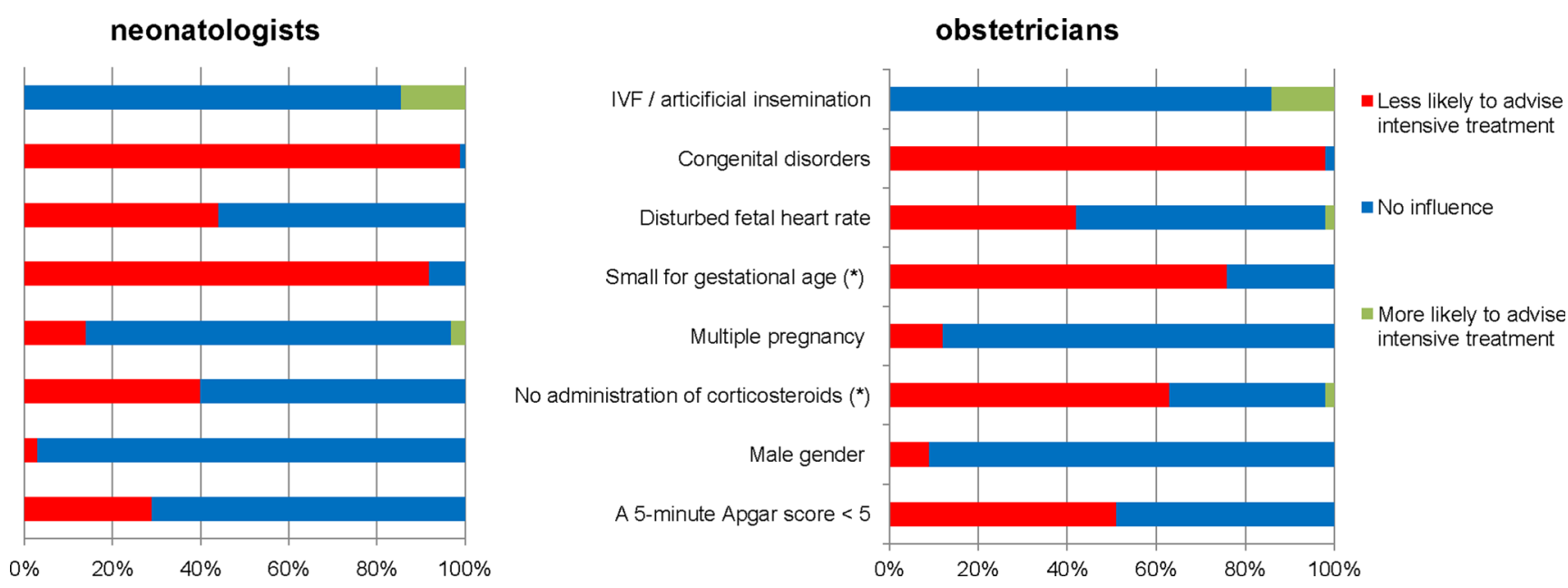

Fig. 3 Factors influencing potential recommendation towards parents for initiating intensive treatment. (*)Significantly different between neonatologists and obstetricians: no corticosteroids p 0.012, SGA p 0.028 
chance of a good outcome, there are situations in which neonatologists should nonetheless defer to parental nontreatment decisions'; however, no specific recommendation for 26 and 27 weeks GA is given [21]. Haward suggests that professional organizations should make guidelines on treatment decisions in extreme prematurity based on the best-interest principle [15]. To the best of our knowledge, there are no papers commenting on an upper limit in terms of GA where parental preferences can be followed including the legal aspects of this.

\section{Decisions or interventions associated with prematurity}

The personal lower limit for certain treatment decisions associated with prematurity varied up to 4 weeks between individuals. It is known that personal preferences can influence counseling and decision-making [34]. For the interventions covered in the Dutch guideline, our results are fairly consistent with the guideline recommendations (transfer to a tertiary center at $23^{+4 / 7}$ weeks GA and administration of corticosteroids at $23^{+5 / 7}$ weeks GA). For these, 59 and $95 \%$, respectively, of all perinatal professionals have their lower limit at our below that mentioned GA, fulfilling the requirements of guideline. It should although be taken into account that the referring gynecologists (non-third line) were not questioned. Other interventions/decisions show large variation. According to the Dutch guideline, a CS at $24^{+0 /}$ ${ }^{7}$ weeks GA on fetal indication can be considered only in case of a spontaneously started delivery and after discussion with parents. Participants indicated $25^{+0 / 7}$ weeks of GA as median lower limit, with a wide variation. Tucker Edmonds recently showed that obstetricians had a personal cutoff for performing a $\mathrm{CS}$ at a later GA (median $25^{+0 / 7}$ weeks GA) than the institutional cutoff (median 24 $4^{+0 / 7}$ weeks GA) [34]. Having a neonatologist present at delivery and intubation after birth when necessary both showed a median lower limit at $24^{+0 / 7}$ weeks of gestation, with relatively little variation; probably because these two items are seen as the minimum conditions that must be met when offering intensive care at $24^{+0 / 7}$ weeks (and implicitly covered in our guideline). However, there was a much wider range for providing chest compressions (when applicable) and administration of epinephrine. The reason for this wide range might be that they are not covered in the Dutch guideline. Compared to surveys from Finland, UK, and the USA, Dutch physicians seem to prefer almost all interventions at a later GA than their colleagues from mentioned countries $[5,32,34]$.

Regarding the differences between obstetricians and neonatologists, for two items, obstetricians preferred significant lower limits than neonatologists (both chest compressions and epinephrine: median lower limit $25^{+0 / 7}$ weeks GA for obstetricians and $26^{+0 / 7}$ weeks GA for neonatologists). Apparently, obstetricians believe that intensive resuscitation can be provided at an earlier GA than their neonatal counterparts, which is contradictory to findings from England by Chan et al. (neonatal staff wished to be more interventional at earlier GA) and also from Finland by Taittonen et al. (pediatric personnel demonstrated more proactive attitudes to the treatment of a premature birth and baby than obstetric personnel) [5, 32]. Obstetricians do not normally perform these parts of resuscitation, so perhaps it was harder for them to comment on these items. However, obstetricians and neonatologists should participate as a team in taking care for mothers and newborns at the limits of viability; including agreement on the extent of potential neonatal resuscitation. Differences in opinions should be solved and no conflicts on care should arise [5, $10,32]$.

\section{Role of associated factors}

Individual prognostic factors do play a role in prenatal counseling at 24 weeks of GA for Dutch physicians, mainly a congenital disorder. Tyson et al. described four factors next to GA to have an impact on predicting outcome: birth weight, sex, (non)exposure to antenatal corticosteroids, and single/ multiple gestation. These factors have a varying impact in this survey; for (male) gender and a multiple pregnancy $<15 \%$ of participants are less likely to advise intensive treatment. The two other factors from Tyson's prediction model seem to have a greater impact; being SGA and no corticosteroids administered [35]. Although these two have an impact for both specialties, the proportion that agrees differs between them. We do not know why "no corticosteroids administered" is more important for obstetricians, and a "SGA infant" is more important for neonatologists. It is speculating, however, that these factors might be more visible within their specific expertise/field of work.

In contrast to Tyson, we did not try to quantify the prognostic factors and only asked for an influence. The Dutch guideline states that the factors from the Tyson model "can be taken into account"; however, since the value of these prognostic factors is unknown for the Dutch population, no specific recommendations are given. In 2014 though, 3 years after introduction of the guideline and after this survey was done, Dutch data showed that no antenatal corticosteroids, male gender, maternal age $>35$ years, Caucasian ethnicity, non-cephalic presentation, and birth outside a level III hospital were predictors for mortality (together with GA) in a prematurity cohort of GA $25^{0}-31^{6}$ [29]. This survey shows that some factors were taken into account in prenatal consultation at 24 weeks GA. Nevertheless, we should allow for an individual approach to these prognostic factors, since the models are mostly not developed for counseling decisions and, most important, they do not predict an individual course. However, these factors might be helpful in addition to the GA to identify the potential range of outcome. 


\section{Strengths and limitations}

The strongest aspects of this study are the national level of the survey (all Dutch tertiary centers where included) representing our national situation. Also, the fact that most of the questions are directly related to content of the national guideline on perinatal practice makes it relevant for daily practice.

This study also has limitations. Some degree of selectionbias cannot be ruled out. The character of the survey (asking for recommendations to parents and personal lower limits for certain decisions) might not be representative for actual practice; however, no less relevant since it is known that, despite guidelines or local policies, personal preferences influence decision-making [34]. Because of the long inclusion period (16 months) effects of experience or learning cannot be ruled out, and it is unsure to what extent results from this Dutch cohort can be generalized to the international situation. However, many countries do have guidelines, so the general conclusion on variety between individuals and between professions despite guidelines might be applicable.

\section{Conclusions and future perspectives}

This is the first study to asses physicians' opinions on treatment decisions at the threshold of viability in the Netherlands. There was a wide variety in preferred treatment decisions at the limits of viability and in perceived lower limits of treatment between individual professionals. This variation was especially observed when aspects were not covered in the Dutch national guideline on perinatal practice in extreme prematurity. Furthermore, obstetricians and neonatologists disagreed on some aspects, particularly lower limits of GA for cardiac resuscitation and the influence of patient characteristics on initiating care. This variety and disagreement can lead to unwanted practice variation.

When items are covered in a guideline it seems to reduce, but not to exclude, variation. Especially when a guideline leaves room for interpretation, personal opinions will become more important. Revision of guidelines to cover more aspects might be a solution. However, more strict guidelines and recommendations that are based on national consensus need not interfere with an individualized approach, since making different choices based on patient characteristics and parental preferences are part of this consensus. The current study showed that in similar cases, dealing with different caregivers, different decisions can be made. At the limits of viability, it covers, by definition, decisions about life and death and practice variation is therefore even more unwanted.

Acknowledgments The authors would like to thank all authors who shared their survey with us $[1,3,5,18,19,27]$
The authors would like to thank all participating Dutch obstetricians and neonatologists.

Authors' contributions RG, JD, $\mathrm{AvH}$, and $\mathrm{MH}$ had the core idea for this study. RG, JD, AvH, MW, MH, and $\mathrm{RH}$ prepared the questionnaire. All authors either analyzed the data or interpreted the results. RG wrote the draft of the article. All other authors commented on the manuscript.

Compliance with ethical standards This study was not funded. All procedures performed in this study were in accordance with the ethical standard. In the Netherlands, there is no need for a survey study to be validated by an ethics committee. The local institutional review board confirmed this.

Conflict of interest The authors declare that they have no conflict of interest.

Open Access This article is distributed under the terms of the Creative Commons Attribution 4.0 International License (http:// creativecommons.org/licenses/by/4.0/), which permits unrestricted use, distribution, and reproduction in any medium, provided you give appropriate credit to the original author(s) and the source, provide a link to the Creative Commons license, and indicate if changes were made.

\section{References}

1. Bastek TK, Richardson DK, Zupancic JA, Burns JP (2005) Prenatal consultation practices at the border of viability: a regional survey. Pediatrics 116:407-413

2. Bode MM, D'Eugenio DB, Forsyth N, Coleman J, Gross CR, Gross SJ (2009) Outcome of extreme prematurity: a prospective comparison of 2 regional cohorts born 20 years apart. Pediatrics 124:866874

3. Boss RD, Hutton N, Sulpar LJ, West AM, Donohue PK (2008) Values parents apply to decision-making regarding delivery room resuscitation for high-risk newborns. Pediatrics 122:583-589

4. Brunkhorst J, Weiner J, Lantos J (2014) Infants of borderline viability: the ethics of delivery room care. Semin Fetal Neonatal Med 19:290-295

5. Chan KL, Kean LH, Marlow N (2006) Staff views on the management of the extremely preterm infant. Eur J Obstet Gynecol Reprod Biol 128:142-147

6. Condie J, Caldarelli L, Tarr L, Gray C, Rodriquez T, Lantos J, Meadow W (2013) Have the boundaries of the 'grey zone' of perinatal resuscitation changed for extremely preterm infants over 20 years? Acta Paediatr 102:258-262

7. Cuttini M, Rebagliato M, Bortoli P, Hansen G, de Leeuw R, Lenoir S, Persson J, Reid M, Schroell M, de Vonderweid U, Kaminski M, Lenard H, Orzalesi M, Saracci R (1999) Parental visiting, communication, and participation in ethical decisions: a comparison of neonatal unit policies in Europe. Arch Dis Child Fetal Neonatal Ed 81:F84-91

8. de Laat MW, Wiegerinck MM, Walther FJ, Boluyt N, Mol BW, van der Post JA, van Lith JM, Offringa M, Nederlandse Vereniging voor K, Nederlandse Vereniging voor Obstetrie en G (2010) Practice guideline 'Perinatal management of extremely preterm delivery'. Ned Tijdschr Geneeskd 154, A2701

9. Duffy D, Reynolds P (2011) Babies born at the threshold of viability: attitudes of paediatric consultants and trainees in South East England. Acta Paediatr 100:42-46 
10. Gallagher K, Martin J, Keller M, Marlow N (2014) European variation in decision-making and parental involvement during preterm birth. Arch Dis Child Fetal Neonatal Ed 99:F245-249

11. Geurtzen R, Hogeveen M, Rajani AK, Chitkara R, Antonius T, van Heijst A, Draaisma J, Halamek LP (2014) Using simulation to study difficult clinical issues: prenatal counseling at the threshold of viability across American and Dutch cultures. Simul Healthc 9:167173

12. Geurtzen R, van Heijst AF, Babarao S, Molloy E, Draaisma JM, Hogeveen M (2016) Practices in antenatal counselling for extremely premature infants amongst European trainees. J Matern Fetal Neonatal Med:1-10

13. Guillen U, Weiss EM, Munson D, Maton P, Jefferies A, Norman M, Naulaers G, Mendes J, Justo da Silva L, Zoban P, Hansen TW, Hallman M, Delivoria-Papadopoulos M, Hosono S, Albersheim SG, Williams C, Boyle E, Lui K, Darlow B, Kirpalani H (2015) Guidelines for the management of extremely premature deliveries: a systematic review. Pediatrics 136:343-350

14. Hakansson S, Farooqi A, Holmgren PA, Serenius F, Hogberg U (2004) Proactive management promotes outcome in extremely preterm infants: a population-based comparison of two perinatal management strategies. Pediatrics 114:58-64

15. Haward MF, Kirshenbaum NW, Campbell DE (2011) Care at the edge of viability: medical and ethical issues. Clin Perinatol 38:471492

16. Haward MF, Murphy RO, Lorenz JM (2012) Default options and neonatal resuscitation decisions. J Med Ethics 38:713-718

17. Janvier A, Barrington K, Deschenes M, Couture E, Nadeau S, Lantos J (2008) Relationship between site of training and residents' attitudes about neonatal resuscitation. Arch Pediatr Adolesc Med 162:532-537

18. Kaempf JW, Tomlinson M, Arduza C, Anderson S, Campbell B, Ferguson LA, Zabari M, Stewart VT (2006) Medical staff guidelines for periviability pregnancy counseling and medical treatment of extremely premature infants. Pediatrics 117:22-29

19. Kavanaugh K, Savage T, Kilpatrick S, Kimura R, Hershberger P (2005) Life support decisions for extremely premature infants: report of a pilot study. J Pediatr Nurs 20:347-359

20. Khan RA, Burgoyne L, O'Connell MP, Dempsey EM (2009) Resuscitation at the limits of viability - an Irish perspective. Acta Paediatr 98:1456-1460

21. Kipnis K (2007) Harm and uncertainty in newborn intensive care. Theor Med Bioeth 28:393-412

22. Kollee LA, Cuttini M, Delmas D, Papiernik E, den Ouden AL, Agostino R, Boerch K, Breart G, Chabernaud JL, Draper ES, Gortner L, Kunzel W, Maier RF, Mazela J, Milligan D, Van Reempts P, Weber T, Zeitlin J, group MR (2009) Obstetric interventions for babies born before 28 weeks of gestation in Europe: results of the MOSAIC study. BJOG 116:1481-1491
23. Lantos JD (2015) International and cross-cultural dimensions of treatment decisions for neonates. Semin Fetal Neonatal Med

24. Lavin JP Jr, Kantak A, Ohlinger J, Kaempf JW, Tomlinson M, Campbell B, Fofah O, Edwards W, Allbright K, Hagen E, Suresh G, Schriefer J (2006) Attitudes of obstetric and pediatric health care providers toward resuscitation of infants who are born at the margins of viability. Pediatrics 118(Suppl 2):S169-176

25. Lorenz JM, Paneth N, Jetton JR, den Ouden L, Tyson JE (2001) Comparison of management strategies for extreme prematurity in New Jersey and the Netherlands: outcomes and resource expenditure. Pediatrics 108:1269-1274

26. Morgan MA, Goldenberg RL, Schulkin J (2008) Obstetrician-gynecologists' practices regarding preterm birth at the limit of viability. J Matern Fetal Neonatal Med 21:115-121

27. Partridge JC, Martinez AM, Nishida H, Boo NY, Tan KW, Yeung $\mathrm{CY}, \mathrm{Lu} \mathrm{JH}, \mathrm{Yu} \mathrm{VY}$ (2005) International comparison of care for very low birth weight infants: parents' perceptions of counseling and decision-making. Pediatrics 116:e263-271

28. Pignotti MS, Donzelli G (2008) Perinatal care at the threshold of viability: an international comparison of practical guidelines for the treatment of extremely preterm births. Pediatrics 121:e193-198

29. Ravelli AC, Schaaf JM, Mol BW, Tamminga P, Eskes M, van der Post JA, Abu-Hanna A (2014) Antenatal prediction of neonatal mortality in very premature infants. Eur J Obstet Gynecol Reprod Biol 176:126-131

30. Rysavy MA, Li L, Bell EF, Das A, Hintz SR, Stoll BJ, Vohr BR, Carlo WA, Shankaran S, Walsh MC, Tyson JE, Cotten CM, Smith PB, Murray JC, Colaizy TT, Brumbaugh JE, Higgins RD, Eunice Kennedy Shriver National Institute of Child H, Human Development Neonatal Research N (2015) Between-hospital variation in treatment and outcomes in extremely preterm infants. $\mathrm{N}$ Engl J Med 372:1801-1811

31. Seri I, Evans J (2008) Limits of viability: definition of the gray zone. J Perinatol 28(Suppl 1):S4-8

32. Taittonen L, Korhonen P, Palomaki O, Luukkaala T, Tammela O (2014) Opinions on the counselling, care and outcome of extremely premature birth among healthcare professionals in Finland. Acta Paediatr 103:262-267

33. Tomlinson MW, Kaempf JW, Ferguson LA, Stewart VT (2010) Caring for the pregnant woman presenting at periviable gestation: acknowledging the ambiguity and uncertainty. Am J Obstet Gynecol 202:529, e521-526

34. Tucker Edmonds B, McKenzie F, Farrow V, Raglan G, Schulkin J (2015) A national survey of obstetricians' attitudes toward and practice of periviable intervention. J Perinatol 35: 338-343

35. Tyson JE, Parikh NA, Langer J, Green C, Higgins RD, National Institute of Child $\mathrm{H}$, Human Development Neonatal Research $\mathrm{N}$ (2008) Intensive care for extreme prematurity-moving beyond gestational age. N Engl J Med 358:1672-1681 